\title{
Rivaroxaban versus enoxaparin/vitamin K antagonist therapy in patients with venous thromboembolism and renal impairment
}

\author{
Rupert M Bauersachs ${ }^{1 *}$, Anthonie WA Lensing ${ }^{2}$, Martin H Prins ${ }^{3}$, Dagmar Kubitza ${ }^{2}$, Ákos F Pap ${ }^{2}$, Hervé Decousus ${ }^{4}$, \\ Jan Beyer-Westendorf ${ }^{5}$ and Paolo Prandoni ${ }^{6}$
}

\begin{abstract}
Background: Patients with renal impairment receiving classical anticoagulation for venous thromboembolism (VTE) are at increased risk of bleeding and possibly pulmonary embolism. We examined the efficacy and safety of oral rivaroxaban in patients with VTE with and without renal impairment.

Methods: Prespecified subgroup analysis of the EINSTEIN DVT and EINSTEIN PE studies comparing fixed-dose rivaroxaban with enoxaparin/a vitamin K antagonist (VKA), performed in 8246 patients enrolled from 2007 to 2011 in 314 hospitals.

Results: Outcomes were recurrent VTE and major or clinically relevant nonmajor bleeding in patients with normal renal function $(n=5569 ; 67.3 \%)$ or mild $(n=2037 ; 24.6 \%)$, moderate $(n=636 ; 7.7 \%)$, or severe $(n=21 ; 0.3 \%)$ renal impairment. Rates of recurrent VTE were $1.8 \%, 2.8 \%, 3.3 \%$, and $4.8 \%$ in patients with normal renal function and mild, moderate, and severe renal impairment, respectively $\left(p_{\text {trend }}=0.001\right)$. Hazard ratios for recurrent VTE were similar between treatment groups across renal function categories ( $p_{\text {interaction }}=0.72$ ). Major bleeding in rivaroxaban recipients occurred in $0.8 \%, 1.4 \%, 0.9 \%$, and $0 \%$, respectively ( $p_{\text {trend }}=0.50$ ). Respective rates in enoxaparin NKA recipients were $1.0 \%, 3.0 \%, 3.9 \%$, and $9.1 \%$ ( $p_{\text {trend }}<0.001$ ). Rivaroxaban-enoxaparin/NKA hazard ratios were 0.79 (95\% confidence interval [Cl] 0.46-1.36) for normal renal function, 0.44 (95\% Cl $0.24-0.84$ ) for mild renal impairment, and $0.23(95 \% \mathrm{Cl} 0.06-0.81)$ for moderate renal impairment ( $\left.p_{\text {interaction }}=0.034\right)$.
\end{abstract}

Conclusions: Patients with symptomatic VTE and renal impairment are at increased risk of recurrent VTE. Renal impairment increased the risk of major bleeding in enoxaparin/NKA-treated patients but not in rivaroxaban-treated patients.

Trial registration: NCT00440193 and NCT00439777.

Keywords: Anticoagulants, Bleeding, Renal insufficiency, Rivaroxaban, Venous thromboembolism

\section{Background}

Rivaroxaban is an oral, direct Factor Xa inhibitor with predictable pharmacokinetic and pharmacodynamic properties, which obviate the need for routine coagulation monitoring, and a rapid onset of action, with a peak anticoagulant effect within 2 to $4 \mathrm{~h}$ after dosing [1,2]. Pharmacokinetic studies showed that rivaroxaban has a dual mode of elimination; approximately two-thirds of

\footnotetext{
*Correspondence: bauersachs@em.uni-frankfurt.de

'Department of Vascular Medicine, Klinikum Darmstadt GmbH, Grafenstraße 9, 64283, Darmstadt, Germany

Full list of author information is available at the end of the article
}

orally administered rivaroxaban is inactivated by metabolic degradation, of which half is eliminated renally and the other half eliminated by the hepatobiliary route. The final one-third of the administered dose undergoes renal excretion as unchanged active substance in the urine, mainly via active renal secretion [3]. Consequently, rivaroxaban exposure increases modestly with declining creatinine clearance $(\mathrm{CrCl})$, with an increase in the area under the plasma concentration-time curve (AUC) of $44 \%, 52 \%$, and $64 \%$ in patients with mild $(\mathrm{CrCl} 50-79 \mathrm{ml} / \mathrm{min})$, moderate $(\mathrm{CrCl} 30-49 \mathrm{ml} / \mathrm{min})$, and severe $(\mathrm{CrCl}<30 \mathrm{ml} / \mathrm{min})$ renal impairment, respectively [4]. The maximum concentrations

\section{Biomed Central}

(c) 2014 Bauersachs et al.; licensee BioMed Central Ltd. This is an Open Access article distributed under the terms of the Creative Commons Attribution License (http://creativecommons.org/licenses/by/4.0), which permits unrestricted use, distribution, and reproduction in any medium, provided the original work is properly credited. The Creative Commons Public Domain Dedication waiver (http://creativecommons.org/publicdomain/zero/1.0/) applies to the data made available in this article, unless otherwise stated. 
of rivaroxaban compared with patients with normal $\mathrm{CrCl}$ (i.e. $\geq 80 \mathrm{ml} / \mathrm{min}$ ) also showed modest increases of $28 \%$, $12 \%$, and $26 \%$, respectively [4]. In addition, the half-life of rivaroxaban was slightly prolonged by $0.4,0.7$, and $1.2 \mathrm{~h}$, respectively [4].

Anticoagulant treatment is associated with an increased risk of bleeding. Because rivaroxaban is partly excreted renally, a dose reduction in patients with renal impairment would seem plausible. However, severe renal impairment has been associated with an increase in the incidence of fatal pulmonary embolism (PE) within the first 2 weeks of diagnosis, which exceeded the risk of fatal bleeding by far, in a prospective registry of patients with symptomatic venous thromboembolism (VTE) treated with low molecular weight heparins and vitamin $\mathrm{K}$ antagonists (VKAs) [5]. In addition, moderate or severe renal impairment was recently identified as a risk factor for a first episode of symptomatic venous thrombosis [6]. Consequently, it is important to understand the effect of renal impairment on the efficacy and safety of rivaroxaban in VTE patients to minimize the risk of bleeding while ensuring optimal anticoagulation in patients with renal impairment.

In two large rivaroxaban dose-finding studies in patients with symptomatic deep vein thrombosis (DVT) that evaluated daily rivaroxaban doses between $20 \mathrm{mg}$ and $60 \mathrm{mg}$, all doses were associated with low rates of recurrent VTE and major bleeding $[7,8]$. In addition, there was no increased risk of major bleeding with declining kidney function [8]. As a consequence, the rivaroxaban regimen selected for the phase III studies of VTE treatment consisted of $15 \mathrm{mg}$ twice-daily doses for 3 weeks, followed by $20 \mathrm{mg}$ once daily without dose adaptations for mild-to-moderate renal impairment.

Here, we report on the incidences of recurrent VTE and bleeding in patients with and without renal impairment who participated in the EINSTEIN DVT and EINSTEIN PE studies $[9,10]$.

\section{Methods}

\section{Study design}

The EINSTEIN DVT and EINSTEIN PE studies were open-label, randomized, event-driven, noninferiority studies that compared oral rivaroxaban alone (15 mg twice daily for 3 weeks, followed by $20 \mathrm{mg}$ once daily) with subcutaneous enoxaparin followed by a VKA (either warfarin or acenocoumarol; target international normalized ratio [INR] 2.0-3.0) for 3, 6, or 12 months in patients with acute, symptomatic DVT and/or PE $[9,10]$.

Exclusion criteria for both studies were another indication for a VKA; a calculated $\mathrm{CrCl}<30 \mathrm{ml} / \mathrm{min}$ using the Cockcroft-Gault formula [11]; clinically significant liver disease or an alanine aminotransferase level that was three times the upper limit of the normal range or higher; bacterial endocarditis; active bleeding or a high risk of bleeding, contraindicating anticoagulant treatment; systolic blood pressure $>180 \mathrm{~mm} \mathrm{Hg}$ or diastolic blood pressure $>110 \mathrm{~mm} \mathrm{Hg}$; childbearing potential without proper contraceptive measures, pregnancy, or breastfeeding; concomitant use of strong cytochrome P450 3A4 inhibitors (e.g. human immunodeficiency virus protease inhibitors or systemic ketoconazole) or inducers (e.g. rifampicin, carbamazepine, or phenytoin); participation in another experimental pharmacotherapeutic program within 30 days before screening; and a life expectancy of $<3$ months.

An independent committee, unaware of treatment assignment, adjudicated all suspected study outcomes. Symptomatic recurrent VTE was defined as a composite of fatal or nonfatal PE or DVT on the basis of criteria that have been described previously [9,10]. Death was classified as due to PE, bleeding, or other established causes or diagnoses. PE was considered the cause of death if there was objective documentation of the condition or if death could not be attributed to a documented cause and PE could not be confidently ruled out.

Bleeding was classified as major or clinically relevant nonmajor bleeding, as described previously [9,10,12]. Bleeding was major if it was clinically overt and was associated with a decrease in the hemoglobin level of $\geq 2.0 \mathrm{~g} / \mathrm{dl}$; if bleeding led to the transfusion of $\geq 2$ units of red cells; or if bleeding was intracranial or retroperitoneal, occurred in another critical site, or contributed to death. Clinically relevant nonmajor bleeding was defined as overt bleeding that did not meet the criteria for major bleeding but was associated with medical intervention, unscheduled contact with a physician, interruption or discontinuation of a study drug, or discomfort or impairment of daily activities.

EINSTEIN study patient data were obtained after informed consent. Ethical approval was obtained from the IRBs of all institutions involved in the EINSTEIN studies [13]. Data from the EINSTEIN studies' databases had been entirely de-linked from personal health information when accessed for this study. This study is consistent with the principles of the Declaration of Helsinki. Bayer and Janssen sponsored the two EINSTEIN clinical trials, collected and maintained the data, and performed the analyses that the authors requested.

\section{Statistical analysis}

Analyses were performed in SAS version 9.2 (SAS Institute Inc., Cary, NC, USA). Time to efficacy and bleeding outcomes were analyzed using Cox proportional-hazards models stratified according to the intended duration of treatment, with adjustment for absence of active cancer at baseline in each model and including renal function categories, as detailed below. For efficacy, this was based on the intention-to-treat population for the intended 
treatment period, and for safety, on all patients who received at least one dose of study drug for the period up to 2 days after the last dose.

Renal function was categorized as normal (i.e. $\mathrm{CrCl}$ $\geq 80 \mathrm{ml} / \mathrm{min}$ ), or with impairment that was mild $(\mathrm{CrCl}$ $50-79 \mathrm{ml} / \mathrm{min})$, moderate $(\mathrm{CrCl} 30-49 \mathrm{ml} / \mathrm{min})$, or severe $(\mathrm{CrCl}<30 \mathrm{ml} / \mathrm{min})$. The effects of renal function on rates of recurrent VTE and bleeding were tested by including renal function categories in the Cox proportional-hazards models as a single covariate $\left(\chi^{2}\right.$ test for trend with 1 degree of freedom). In addition, to test whether this trend was different across treatment groups, the relevant interaction term was included in the model $\left(\chi^{2}\right.$ test for interaction of trends by treatment group with 1 degree of freedom). In 9 patients, $\mathrm{CrCl}$ values were calculated using the abbreviated Modification of Diet in Renal Disease equation [14], because body weight was not available. Furthermore, separate Cox regression models were fitted to investigate the treatment effect within each renal function category. To allow for comparison between the period of initial bridging treatment with renally cleared low molecular weight heparin alongside hepatically metabolized warfarin or acenocoumarol, and the treatment period with VKA alone, the incidences of outcomes in the population at risk were calculated separately up to Day 14 and for the full study period after Day 14.

\section{Results}

\section{Patient demographics}

In the EINSTEIN DVT and EINSTEIN PE studies combined, 4150 patients were assigned to rivaroxaban and 4131 were assigned to enoxaparin/VKA [13]. A total of 5569 (67.3\%) patients had normal renal function (40.5\% female; mean age 49.9 years), 2037 (24.6\%) patients had mild renal impairment $(52.7 \%$ female; mean age 69.6 years), 636 (7.7\%) patients had moderate renal impairment (65.9\% female; mean age 78.2 years), and $21(0.3 \%)$ patients had severe renal impairment $(76.2 \%$ female; mean age 76.8 years). Values for $\mathrm{CrCl}$ were missing in 18 (0.2\%) patients and these were not included in the analysis. The main demographic characteristics within the subgroups were similar for rivaroxaban and enoxaparin/VKA (Table 1) [13].

\section{Recurrent venous thromboembolism and renal function}

Rivaroxaban was noninferior to enoxaparin/VKA for the prevention of recurrent VTE (rivaroxaban, 86 events [2.1\%], enoxaparin/VKA, 95 events [2.3\%]; hazard ratio [HR] 0.89; 95\% confidence interval [CI] 0.66-1.19; $\mathrm{p}<0.001$ for noninferiority margin of 1.75$)[13,15]$.

Rates of recurrent VTE for both treatments combined were $1.8 \%, 2.8 \%, 3.3 \%$, and $4.8 \%$ in patients with normal renal function and mild, moderate, and severe renal impairment, respectively $\left(p_{\text {trend }}=0.001\right)$. The respective incidence
Table 1 Demographic characteristics of EINSTEIN DVT and EINSTEIN PE patients combined

\begin{tabular}{|c|c|c|}
\hline & $\begin{array}{c}\text { Rivaroxaban } \\
n=4150\end{array}$ & $\begin{array}{c}\text { Enoxaparin/VKA } \\
n=4131\end{array}$ \\
\hline Age, median (Q1-Q3), y & $58.0(45.0-71.0)$ & $59.0(45.0-70.0)$ \\
\hline Female sex, n (\%) & $1848(44.5)$ & $1917(46.4)$ \\
\hline Weight, median (Q1-Q3), kg & $80.0(70.0-93.0)$ & $80.0(70.0-93.0)$ \\
\hline \multicolumn{3}{|l|}{ Creatinine clearance } \\
\hline$\geq 80 \mathrm{ml} / \mathrm{min}, \mathrm{n}(\%)$ & $2772(66.8)$ & $2797(67.7)$ \\
\hline Age, median (Q1-Q3), y & $50.0(39.0-61.0)$ & $51.0(40.0-61.0)$ \\
\hline Female sex, n (\%) & $1113(40.2)$ & $1140(40.8)$ \\
\hline Weight, median (Q1-Q3), kg & $85.0(74.0-98.0)$ & $85.0(75.0-98.0)$ \\
\hline 50-79 ml/min, n (\%) & $1036(25.0)$ & $1001(24.2)$ \\
\hline Age, median (Q1-Q3), y & $71.0(64.0-77.0)$ & $71.0(65.0-77.0)$ \\
\hline Female sex, n (\%) & $520(50.2)$ & $553(55.2)$ \\
\hline Weight, median (Q1-Q3), kg & $74.8(65.0-82.0)$ & $74.0(65.0-82.0)$ \\
\hline 30-49 ml/min, n (\%) & $323(7.8)$ & $313(7.6)$ \\
\hline Age, median (Q1-Q3), y & $80.0(75.0-84.0)$ & $79.0(75.0-83.0)$ \\
\hline Female sex, n (\%) & $209(64.7)$ & $210(67.1)$ \\
\hline Weight, median (Q1-Q3), kg & $67.0(59.0-75.1)$ & $67.8(59.0-75.0)$ \\
\hline$<30$ ml/min, n (\%) & $10(0.2)$ & $11(0.3)$ \\
\hline Age, median (Q1-Q3), y & $80.5(73.0-86.0)$ & $79.0(77.0-86.0)$ \\
\hline Female sex, n (\%) & $5(50.0)$ & $11(100.0)$ \\
\hline Weight, median (Q1-Q3), kg & $60.0(50.0-68.0)$ & $70.0(48.0-75.0)$ \\
\hline Missing, n (\%) & $9(0.2)$ & $9(0.2)$ \\
\hline \multicolumn{3}{|l|}{ Risk factors for VTE } \\
\hline Unprovoked VTE, n (\%) & $2003(48.3)$ & 2048 (49.6) \\
\hline Previous VTE, n (\%) & $791(19.1)$ & 819 (19.8) \\
\hline Active cancer, n (\%) & $232(5.6)$ & $198(4.8)$ \\
\hline
\end{tabular}

Q, Quartile; VKA, Vitamin K antagonist; VTE, Venous thromboembolism.

rates for rivaroxaban and enoxaparin/VKA patients are shown in Table 2 and Figure 1. The rivaroxaban-enoxaparin/VKA HRs were similar for those with normal renal function (HR 0.95; 95\% CI 0.65-1.41), for those with mild renal impairment (HR 0.77; 95\% CI 0.45-1.30), and for those with moderate renal impairment (HR 1.05; 95\% CI $0.44-2.47$ ), respectively $\left(p_{\text {interaction }}=0.72\right.$ ). In the subgroup of patients with severe renal impairment, no event occurred in the rivaroxaban group and 1 event occurred in the VKA group.

\section{Bleeding and renal function}

A first major or clinically relevant nonmajor bleeding event occurred in 388 patients (9.4\%) in the rivaroxaban group and in 412 patients $(10.0 \%)$ in the enoxaparin/ VKA group (HR 0.93; 95\% CI 0.81-1.06; $\mathrm{p}=0.27$ ) [13]. In patients receiving rivaroxaban, major and clinically relevant nonmajor bleeding occurred in $8.7 \%$ of patients with normal renal function, in $10.7 \%$ of those with mild 
Table 2 Recurrent VTE and bleeding in relation to renal function, treatment, and treatment period: EINSTEIN DVT and EINSTEIN PE patients combined*

\begin{tabular}{|c|c|c|c|c|c|c|}
\hline & \multicolumn{2}{|c|}{ Entire analysis period } & \multicolumn{2}{|c|}{ Period up to 14 days } & \multicolumn{2}{|c|}{ Period after 14 days } \\
\hline & Rivaroxaban & Enoxaparin/VKA & Rivaroxaban & Enoxaparin/VKA & Rivaroxaban & Enoxaparin/VKA \\
\hline & $n=4150$ & $n=4131$ & $n=4150$ & $n=4131$ & $n=4054$ & $n=4001$ \\
\hline \multicolumn{7}{|l|}{ Recurrent VTE n/N (\%) } \\
\hline Total of recurrent VTE & 86 & 95 & 38 & 37 & 48 & 58 \\
\hline Normal renal function & $50 / 2772(1.8)$ & $52 / 2797(1.9)$ & 23/2772 (0.8) & 26/2797 (0.9) & $27 / 2720(1.0)$ & 26/2716 (1.0) \\
\hline Mild renal impairment & 25/1036 (2.4) & $31 / 1001(3.1)$ & 10/1036 (1.0) & 8/1001 (0.8) & 15/1009 (1.5) & 23/974 (2.4) \\
\hline Moderate renal impairment & $11 / 323(3.4)$ & 10/313 (3.2) & $5 / 323(1.5)$ & 2/313 (0.6) & $6 / 307(2.0)$ & $8 / 296(2.7)$ \\
\hline Severe renal impairment & $0 / 10(0)$ & $1 / 11(9.1)$ & $0 / 10(0)$ & $1 / 11(9.1)$ & $0 / 10(0)$ & $0 / 8(0)$ \\
\hline Missing & $0 / 9(0)$ & $1 / 9(11.1)$ & $0 / 9(0)$ & 0/9 (0) & $0 / 8(0)$ & 1/7 (14.3) \\
\hline \multicolumn{7}{|l|}{ Major bleeding n/N (\%) } \\
\hline Total of major bleeding events & 40 & 72 & 13 & 27 & 27 & 45 \\
\hline Normal renal function & 23/2763 (0.8) & 29/2786 (1.0) & $8 / 2763(0.3)$ & $11 / 2786(0.4)$ & $15 / 2689(0.6)$ & 18/2704 (0.7) \\
\hline Mild renal impairment & 14/1030 (1.4) & $30 / 1002(3.0)$ & $5 / 1030(0.5)$ & 10/1002 (1.0) & 9/985 (0.9) & 20/954 (2.1) \\
\hline Moderate renal impairment & $3 / 320(0.9)$ & 12/310 (3.9) & $0 / 320(0)$ & $5 / 310(1.6)$ & $3 / 305(1.0)$ & $7 / 285(2.5)$ \\
\hline Severe renal impairment & 0/9 (0) & $1 / 11(9.1)$ & $0 / 9(0)$ & $1 / 11(9.1)$ & $0 / 9(0)$ & $0 / 6(0)$ \\
\hline Missing & $0 / 8(0)$ & $0 / 7(0)$ & $0 / 8(0)$ & 0/7 (0) & $0 / 8(0)$ & $0 / 7(0)$ \\
\hline \multicolumn{7}{|c|}{ Major and clinically relevant nonmajor bleeding $n / N$ (\%) } \\
\hline $\begin{array}{l}\text { Total of major and clinically } \\
\text { relevant nonmajor bleeding events }\end{array}$ & 388 & 412 & 129 & 134 & 259 & 278 \\
\hline Normal renal function & 239/2763 (8.7) & 245/2786 (8.8) & $75 / 2763(2.7)$ & $73 / 2786(2.6)$ & $164 / 2627(6.2)$ & $172 / 2646(6.5)$ \\
\hline Mild renal impairment & $110 / 1030(10.7)$ & 123/1002 (12.3) & 40/1030 (3.9) & 40/1002 (4.0) & 70/957 (7.3) & 83/927 (9.0) \\
\hline Moderate renal impairment & $37 / 320(11.6)$ & 43/310 (13.9) & $14 / 320(4.4)$ & 20/310 (6.5) & 23/291 (7.9) & 23/272 (8.5) \\
\hline Severe renal impairment & 2/9 (22.2) & $1 / 11(9.1)$ & $0 / 9(0)$ & 1/11 (9.1) & 2/9 (22.2) & 0/6 (0) \\
\hline Missing & $0 / 8(0)$ & $0 / 7(0)$ & $0 / 8(0)$ & $0 / 7(0)$ & $0 / 8(0)$ & $0 / 7(0)$ \\
\hline
\end{tabular}

VKA, Vitamin K antagonist; VTE, Venous thromboembolism

*Outcomes do not include censored patients or patients who had an event before Day 14.

renal impairment, in $11.6 \%$ of those with moderate renal impairment, and in $22.2 \%$ of those with severe renal impairment $\left(\mathrm{p}_{\text {trend }}=0.013\right)$. In the enoxaparin/VKA group, these incidences were $8.8 \%, 12.3 \%, 13.9 \%$, and $9.1 \%$, respectively ( $p_{\text {trend }}<0.001$ ) (Table 2$)$. The rivaroxabanenoxaparin/VKA HR was 0.98 (95\% CI 0.82-1.18) for patients with normal renal function, 0.85 (95\% CI 0.65-1.09) for those with mild renal impairment, and 0.77 (95\% CI 0.49-1.19) for those with moderate renal impairment $\left(p_{\text {interaction }}=0.29\right)$.

Major bleeding occurred in 40 (1.0\%) rivaroxaban and 72 (1.7\%) enoxaparin/VKA recipients (HR 0.54; 95\% CI $0.37-0.79 ; \mathrm{p}=0.002$; Table 3 ) [13]. In patients receiving rivaroxaban, major bleeding occurred in $0.8 \%$ of patients with normal renal function, in $1.4 \%$ of those with mild renal impairment, in $0.9 \%$ of those with moderate renal impairment, and in $0 \%$ of those with severe renal impairment $\left(\mathrm{p}_{\text {trend }}=0.50\right)$. In the enoxaparin/VKA group, these incidences were $1.0 \%, 3.0 \%, 3.9 \%$, and $9.1 \%$, respectively
( $\mathrm{p}_{\text {trend }}<0.001$ ) (Table 2). The rivaroxaban-enoxaparin/ VKA HRs were 0.79 (95\% CI 0.46-1.36) for those with normal renal function, 0.44 (95\% CI 0.24-0.84) for those with mild renal impairment, and 0.23 (95\% CI 0.06-0.81) for those with moderate renal impairment $\left(p_{\text {interaction }}=0.034\right)$.

The risk of major bleeding was significantly increased in renally impaired patients treated with enoxaparin/ VKA, whereas renal impairment across all stages did not increase major bleeding rates in patients treated with rivaroxaban. The reduction of major bleeding seen in the rivaroxaban group was similarly achieved during the initial treatment period, compared with enoxaparin/ VKA treatment (treatment period up to 14 days), and during long-term treatment, compared with VKA alone (treatment period after 14 days; Table 2).

\section{Discussion}

This analysis of the data accumulated in the EINSTEIN DVT and EINSTEIN PE studies indicated that the risks 

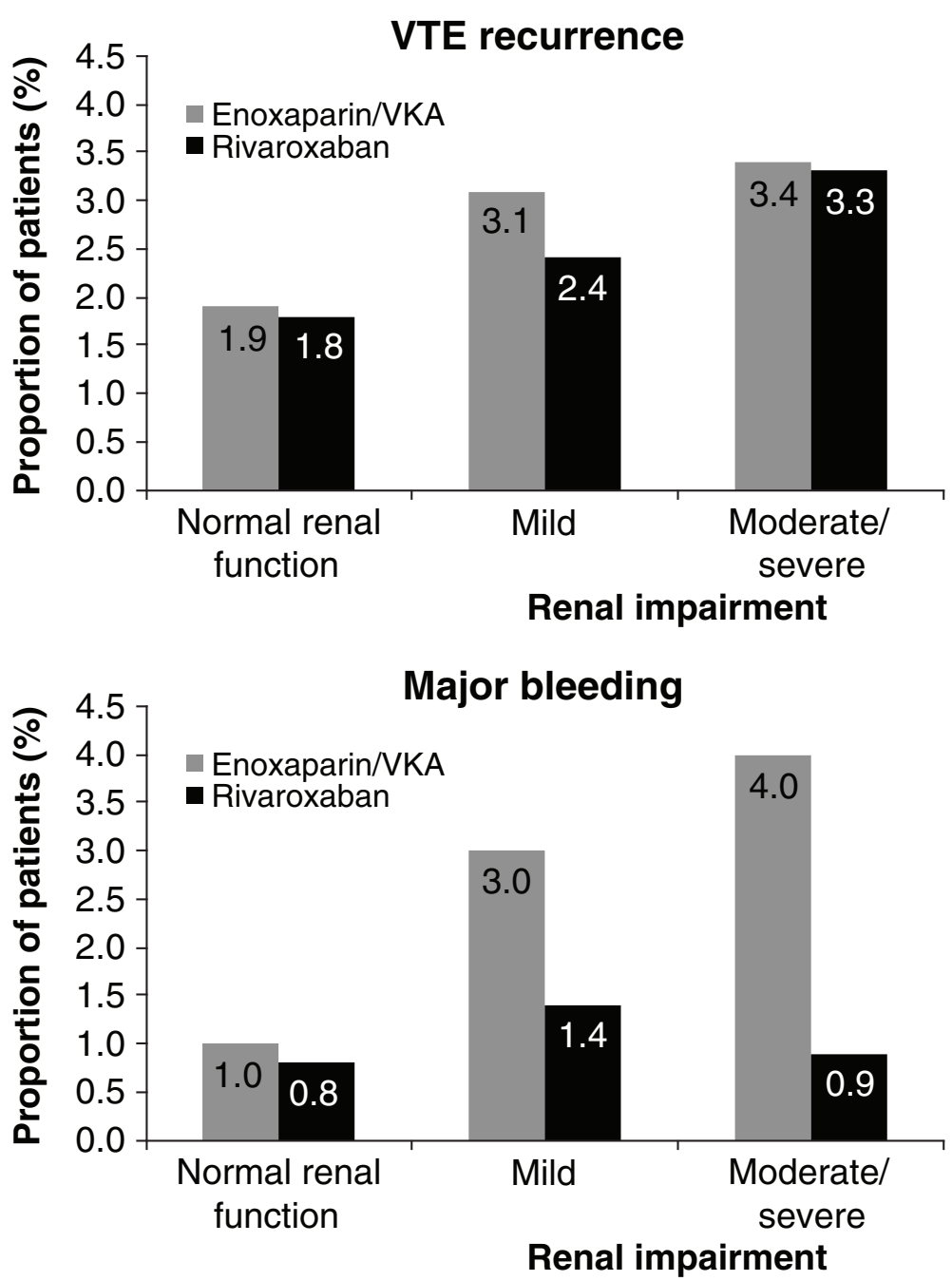

Figure 1 Recurrent VTE and bleeding in relation to renal function across the entire analysis period. EINSTEIN DVT and EINSTEIN PE patients. VKA, vitamin $\mathrm{K}$ antagonist; VTE, venous thromboembolism.

of recurrent VTE and bleeding increase with declining renal function. In addition, the results demonstrated that a dosage of rivaroxaban $15 \mathrm{mg}$ twice daily for 3 weeks, followed by $20 \mathrm{mg}$ once daily, had similar efficacy compared with standard treatment across patients with normal renal function or mild-to-moderate renal impairment. Incidences of the combined outcome of major or clinically relevant nonmajor bleeding were numerically lower with rivaroxaban compared with enoxaparin/VKA. Even more important, there was a significant and clinically important reduction in major bleeding with rivaroxaban compared with enoxaparin/VKA, particularly in patients with mild or moderate renal impairment.

In the EINSTEIN Extension study that compared $20 \mathrm{mg}$ rivaroxaban once daily with placebo for an additional 6 or 12 months in patients who had completed 6-12 months of treatment for VTE, an increased risk of recurrent VTE with declining renal function was also shown [9].
In rivaroxaban recipients with normal renal function or mild, moderate, or severe renal impairment, recurrent VTE occurred in $1.0 \%(4 / 409), 1.4 \%$ (2/147), $4.9 \%(2 / 41)$, and $0 \%$, respectively ( $\mathrm{p}_{\text {trend }}=0.045$ ). In placebo recipients, recurrent VTE occurred in 6.2\% (25/404), 8.0\% (11/138), $10.9 \%(5 / 46)$, and $20.0 \%(1 / 5)$, respectively ( $\left.p_{\text {trend }}=0.045\right)$ [9]. On the other hand, rates of major or clinically relevant nonmajor bleeding in patients receiving rivaroxaban did not significantly increase with declining renal function, since bleeding occurred in 6.4\% (26/406), 6.2\% (9/146), $2.4 \%(1 / 41)$, and $0 \%$ of rivaroxaban recipients with normal renal function or mild, moderate, or severe renal impairment, respectively ( $\mathrm{p}_{\text {trend }}=0.282$ ). In the placebo group, these incidences were $0.7 \%$ (3/402), $0.7 \%$ $(1 / 137), \quad 4.3 \% \quad(2 / 46)$, and $20.0 \%$ (1/5), respectively ( $\left.\mathrm{p}_{\text {trend }}=0.031\right)[9]$.

Because approximately one-third of the administered dose of rivaroxaban is eliminated via the kidneys (as 
Table 3 Presentation of major bleeding for rivaroxaban and enoxaparin/VKA patients separately

\begin{tabular}{|c|c|c|}
\hline & $\begin{array}{l}\text { Rivaroxaban } \\
\qquad n=4130\end{array}$ & $\begin{array}{c}\text { Enoxaparin/ } \\
\text { VKA } \\
n=4116\end{array}$ \\
\hline \multicolumn{3}{|l|}{ First major bleeding, n (\%) } \\
\hline Any & $40(1.0)$ & $72(1.7)$ \\
\hline Fatal bleeding & $3(<0.1)$ & $8(0.2)$ \\
\hline Retroperitoneal & 0 & $1(<0.1)$ \\
\hline Intracranial & $2(<0.1)$ & $4(0.1)$ \\
\hline Gastrointestinal & $1(<0.1)$ & $2(<0.1)$ \\
\hline Thorax & 0 & $1(<0.1)$ \\
\hline Nonfatal bleeding in a critical site & $10(0.2)$ & $27(0.7)$ \\
\hline Retroperitoneal & $1(<0.1)$ & $7(0.2)$ \\
\hline Intracranial & $3(<0.1)$ & $9(0.2)$ \\
\hline Intraocular & $3(<0.1)$ & $3(<0.1)$ \\
\hline Pericardial & 0 & $2(<0.1)$ \\
\hline Intra-articular & 0 & $4(0.1)$ \\
\hline Adrenal & $1(<0.1)$ & 0 \\
\hline Pulmonary & $1(<0.1)$ & 0 \\
\hline Abdominal & $1(<0.1)$ & $2(<0.1)$ \\
\hline $\begin{array}{l}\text { Nonfatal, noncritical site bleeding but } \\
\text { associated with a fall in hemoglobin } \\
\geq 2 \mathrm{~g} / \mathrm{dl} \text { and/or transfusions } \geq 2 \text { units }\end{array}$ & $27(0.7)$ & $37(0.9)$ \\
\hline Surgical site & 0 & $3(<0.1)$ \\
\hline Skin & $1(<0.1)$ & $5(0.1)$ \\
\hline Urogenital & $9(0.2)$ & $3(<0.1)^{*}$ \\
\hline Gastrointestinal & $14(0.3)$ & $24(0.6)$ \\
\hline Nasal & $1(<0.1)$ & 0 \\
\hline Pulmonary & $1(<0.1)$ & 0 \\
\hline Intramuscular & $1(<0.1)$ & $2(<0.1)$ \\
\hline
\end{tabular}

VKA, Vitamin $\mathrm{K}$ antagonist.

*One patient had a combined gastrointestinal/urogenital bleeding event; this event is counted as gastrointestinal only.

unchanged drug) [3], whereas enoxaparin is cleared almost exclusively by the kidneys [16-18], and warfarin/ acenocoumarol by the liver [19-21], it could be expected that the reduction in major bleeding associated with rivaroxaban would be largely obtained during the period of initial treatment during which patients typically receive enoxaparin. However, the distribution of major bleeding over time suggests that the reduced incidence of major bleeding with rivaroxaban is present both during the initial treatment period, when compared with enoxaparin/ VKA treatment, and during long-term treatment, when compared with VKA alone (Table 2). The potential mechanisms behind this observation are subject to speculation. Foremost, in patients with severe renal impairment, rivaroxaban exposure (expressed as AUC) increases by 60\%, whereas the maximum plasma concentration increases by only $\sim 30 \%$, well within its therapeutic window [4]. In addition, the half-life of rivaroxaban increases by only $\sim 1 \mathrm{~h}$ in patients with severe renal impairment, indicating a limited potential for drug accumulation [4]. These modest increases might be the result of a higher fraction of rivaroxaban cleared via several independent hepatic pathways. In addition, patients with renal impairment have been reported to have a higher sensitivity to VKAs, thus requiring smaller dosages and more intensive INR monitoring [21-23]. However, in the EINSTEIN DVT and EINSTEIN PE studies, the time spent above an INR of 3.0 was $15.2 \%$ for patients with normal renal function, $17.6 \%$ for patients with mild renal impairment, and $17.9 \%$ for patients with moderate renal impairment; therefore, a higher sensitivity to VKAs in renally impaired patients cannot fully explain the observed increase in incidence of major bleeding with declining renal function, and further research needs to be done to address this issue.

Some methodological aspects of our analysis warrant comment. First, the analyses of efficacy and safety in subgroups according to renal function were specified $a$ priori. Data were collected prospectively with central adjudication of clinical events by assessors unaware of treatment assignment. The number of patients with mild renal impairment was large, totaling over 2000 patients, whereas the number with moderate renal impairment was substantially smaller, at approximately 600 patients. Severe renal impairment, defined as $\mathrm{CrCl}<30 \mathrm{ml} / \mathrm{min}$, was an exclusion criterion, and few of these patients were randomized. The data collection did not account for significant changes in patients' renal function over the course of treatment.

We identified an increased risk of bleeding in renally impaired patients receiving anticoagulation, but a limitation of our study was the exclusion from participation in the studies of patients with a high bleeding risk or severe renal impairment. Therefore, bleeding rates may be even higher in unselected patients. Owing to the very limited number of patients with severe renal impairment, more cases need to be studied to determine the rate of bleeding.

What are the clinical implications of the present findings? In patients presenting with symptomatic VTE and mild-to-moderate renal impairment, large phase III trials have provided support that rivaroxaban can be administered at a fixed dose without adjustment for renal function and carries a safety advantage compared with standard treatment with enoxaparin/VKA, while maintaining efficacy. The limited increases in exposure, maximum concentration, and half-life of rivaroxaban with declining renal function are similar to those of apixaban [24], but are in contrast to dabigatran, for which exposure increases by $50 \%, 215 \%$, and $530 \%$ and half-life by 2.8, 4.9, and $13.7 \mathrm{~h}$ in patients with mild, moderate, and severe renal impairment, respectively [25]. 
In patients who have a long-term indication for anticoagulation, the use of rivaroxaban seems to be attractive because it may offer a broad safety window for patients with declining renal function that is not covered by the regular monitoring of renal function, which is usually recommended. For patients with severe renal impairment, little evidence is available. Rivaroxaban is not recommended in patients with $\mathrm{CrCl}<15 \mathrm{ml} / \mathrm{min}$, and it should be used with caution in patients with $\mathrm{CrCl} 15-29 \mathrm{ml} / \mathrm{min}$.

\section{Conclusions}

We conclude that both recurrent venous thromboembolic complications and the risk of bleeding increase with declining kidney function in patients with symptomatic DVT or PE. The standard regimen of rivaroxaban, given without a dose reduction, is efficacious and associated with a lower incidence of major bleeding compared with treatment with enoxaparin/VKA.

\section{Abbreviations}

AUC: Area under the concentration-time curve; Cl: Confidence interval; CrCl: Creatinine clearance; DVT: Deep vein thrombosis; HR: Hazard ratio; PE: Pulmonary embolism; Q: Quartile; VKA: Vitamin K antagonist; VTE: Venous thromboembolism.

\section{Competing interests}

RMB has acted as a principal investigator for Germany in anticoagulation studies by Bayer HealthCare Pharmaceuticals, Bristol-Myers Squibb, Boehringer Ingelheim, Daiichi Sankyo, LEO, Novartis, and Pfizer, and has received payment for lectures and speakers bureaus for Bayer HealthCare Pharmaceuticals, Bristol-Myers Squibb, and Daiichi Sankyo. MHP is a consultant advisor for Bayer HealthCare Pharmaceuticals, Daiichi Sankyo, Pfizer, Sanofi, Boehringer Ingelheim, GlaxoSmithKline, LEO, and ThromboGenics. HD has received consultant fees from Bayer HealthCare Pharmaceuticals, Daiichi Sankyo, and GlaxoSmithKline, and has acted as principal investigator in anticoagulation studies for Bayer HealthCare Pharmaceuticals, Daiichi Sankyo, GlaxoSmithKline, and Portola Pharmaceuticals. JBW has received honoraria for lectures and advisory boards from Bayer Pharma, Daiichi Sankyo, Pfizer, Boehringer Ingelheim, Novartis, and Leo Pharma. PP has received consultant fees from Bayer Pharma, Daiichi Sankyo, Pfizer, Boehringer Ingelheim, and Sanofi-Aventis. RMB, MHP, and HD received honoraria from Bayer for steering committee and related work for the EINSTEIN studies. JBW and PP, site principal investigators in the EINSTEIN studies, were paid for time and costs of patient recruitment and follow-up. AWAL, AFP, and DK are employees of Bayer HealthCare Pharmaceuticals. No other competing interests exist.

\section{Authors' contributions}

RMB, AWAL, and MHP contributed to the study concept and design, implementation, interpretation, and analysis of data and drafting of the manuscript. ÁFP performed the statistical analyses and contributed to discussion of the data. All authors contributed to the execution of the study and interpretation of data and study results. All authors contributed to the development of the manuscript and have read and approved the final draft.

\section{Acknowledgments}

The authors would like to acknowledge Hayley Dawson, who provided editorial assistance. Editorial support was funded by Bayer HealthCare Pharmaceuticals and Janssen Scientific Affairs, LLC.

\section{Author details}

'Department of Vascular Medicine, Klinikum Darmstadt GmbH, Grafenstraße 9, 64283, Darmstadt, Germany. ${ }^{2}$ Bayer HealthCare, Wuppertal, Germany. ${ }^{3}$ University of Maastricht, Maastricht, the Netherlands. ${ }^{4}$ Université Jean Monnet, Saint-Etienne, France. ${ }^{5}$ Dresden University Hospital "C.G.Carus", Dresden, Germany. ${ }^{6}$ Department of Medicine, University of Padua, Padua, Italy.
Received: 21 July 2014 Accepted: 14 September 2014

Published: 24 November 2014

\section{References}

1. Mueck W, Lensing AWA, Agnelli G, Décousus H, Prandoni P, Misselwitz F: Rivaroxaban: population pharmacokinetic analyses in patients treated for acute deep-vein thrombosis and exposure simulations in patients with atrial fibrillation treated for stroke prevention. Clin Pharmacokinet 2011, 50:675-686

2. Sarich TC, Peters G, Berkowitz SD, Misselwitz F, Nessel CC, Burton P, CookBruns N, Lensing AW, Haskell L, Perzborn E, Kubitza D, Moore KT, Jalota S, Weber J, Pan G, Sun X, Westermeier T, Nadel A, Oppenheimer L, DiBattiste PM: Rivaroxaban: a novel oral anticoagulant for the prevention and treatment of several thrombosis-mediated conditions. Ann N Y Acad Sci 2013, 1291:42-55.

3. Weinz C, Schwarz T, Kubitza D, Mueck W, Lang D: Metabolism and excretion of rivaroxaban, an oral, direct Factor Xa inhibitor, in rats, dogs and humans. Drug Metab Dispos 2009, 37:1056-1064.

4. Kubitza D, Becka M, Mueck W, Halabi A, Maatouk H, Klause N, Lufft V, Wand DD, Philipp T, Bruck H: Effects of renal impairment on the pharmacokinetics, pharmacodynamics and safety of rivaroxaban, an oral, direct Factor Xa inhibitor. Br J Clin Pharmacol 2010, 70:703-712.

5. Monreal M, Falgá C, Valle R, Barba R, Bosco J, Beato JL, Maestre A, RIETE Investigators: Venous thromboembolism in patients with renal insufficiency: findings from the RIETE Registry. Am J Med 2006, 119:1073-1079.

6. Ocak G, Lijfering WM, Verduijn M, Dekker FW, Rosendaal FR, Cannegieter SC, Vossen CY: Risk of venous thrombosis in patients with chronic kidney disease: identification of high-risk groups. J Thromb Haemost 2013, 11:627-633.

7. Agnelli G, Gallus A, Goldhaber SZ, Haas S, Huisman MV, Hull RD, Kakkar AK, Misselwitz F, Schellong S, ODIXa-DVT Study Investigators: Treatment of proximal deep-vein thrombosis with the oral direct Factor Xa inhibitor rivaroxaban (BAY 59-7939): the ODIXa-DVT (Oral Direct Factor Xa Inhibitor BAY 59-7939 in patients with acute symptomatic Deep-Vein Thrombosis) study. Circulation 2007, 116:180-187.

8. Buller HR, Lensing AWA, Prins MH, Agnelli G, Cohen A, Gallus AS, Misselwitz F, Raskob G, Schellong S, Segers A: A dose-ranging study evaluating once-daily oral administration of the Factor Xa inhibitor rivaroxaban in the treatment of patients with acute symptomatic deep vein thrombosis: the Einstein-DVT Dose-Ranging Study. Blood 2008, 112:2242-2247.

9. The EINSTEIN Investigators: Oral rivaroxaban for symptomatic venous thromboembolism. N Engl J Med 2010, 363:2499-2510.

10. The EINSTEIN-PE Investigators: Oral rivaroxaban for the treatment of symptomatic pulmonary embolism. N Engl J Med 2012, 366:1287-1297.

11. Cockcroft DW, Gault MH: Prediction of creatinine clearance from serum creatinine. Nephron 1976, 16:31-41.

12. Van Gogh Investigators, Büller HR, Cohen AT, Davidson B, Decousus $H$, Gallus AS, Gent M, Pillion G, Piovella F, Prins MH, Raskob GE: Idraparinux versus standard therapy for venous thromboembolic disease. $N$ Engl Med 2007, 357:1094-1104.

13. Prins $M H$, Lensing AWA, Bauersachs $R$, van Bellen $B$, Bounameaux $H_{\text {, }}$ Brighton TA, Cohen AT, Davidson BL, Decousus H, Raskob GE, Berkowitz SD, Wells PS, on behalf of the EINSTEIN Investigators: Oral rivaroxaban versus standard therapy for the treatment of symptomatic venous thromboembolism: a pooled analysis of the EINSTEIN-DVT and PE randomized studies. Thromb J 2013, 11:21.

14. Levey AS, Bosch JP, Lewis JB, Greene T, Rogers N, Roth D: A more accurate method to estimate glomerular filtration rate from serum creatinine: a new prediction equation. Modification of Diet in Renal Disease Study Group. Ann Intern Med 1999, 130:461-470.

15. Prins $\mathrm{MH}$, Lensing AWA: Derivation of the non-inferiority margin for the evaluation of direct oral anticoagulants in the treatment of venous thromboembolism. Thromb J 2013, 11:13.

16. Lim W, Dentali F, Eikelboom JW, Crowther MA: Meta-analysis: low-molecularweight heparin and bleeding in patients with severe renal insufficiency. Ann Intern Med 2006, 144:673-684.

17. Gerlach AT, Pickworth KK, Seth SK, Tanna SB, Barnes JF: Enoxaparin and bleeding complications: a review in patients with and without renal insufficiency. Pharmacotherapy 2000, 20:771-775. 
18. Spinler SA, Inverso SM, Cohen M, Goodman SG, Stringer KA, Antman EM: Safety and efficacy of unfractionated heparin versus enoxaparin in patients who are obese and patients with severe renal impairment: analysis from the ESSENCE and TIMI 11B studies. Am Heart J 2003, 146:33-41.

19. Dreisbach AW, Lertora JJ: The effect of chronic renal failure on drug metabolism and transport. Expert Opin Drug Metab Toxicol 2008, 4:1065-1074.

20. Ansell J, Hirsh J, Hylek E, Jacobson A, Crowther M, Palareti G: Pharmacology and management of the vitamin $\mathrm{K}$ antagonists: American College of Chest Physicians evidence-based clinical practice guidelines (8th Edition). Chest 2008, 133:160S-198S.

21. Kleinow ME, Garwood CL, Clemente JL, Whittaker P: Effect of chronic kidney disease on warfarin management in a pharmacist-managed anticoagulation clinic. J Manag Care Pharm 2011, 17:523-530.

22. Grand'Maison A, Charest AF, Geerts WH: Anticoagulant use in patients with chronic renal impairment. Am J Cardiovasc Drugs 2005, 5:291-305.

23. Limdi NA, Beasley TM, Baird MF, Goldstein JA, McGwin G, Arnett DK, Acton RT, Allon M: Kidney function influences warfarin responsiveness and hemorrhagic complications. J Am Soc Nephrol 2009, 20:912-921.

24. Chang M, Yu Z, Shenker A, Wang J, Pursley J, Boyd R, LaCreta F, Frost C: Apixaban pharmacokinetics and pharmacodynamics in subjects with renal impairment. Clin Pharmacol Drug Dev 2012, 1:185-186.

25. Stangier J, Rathgen K, Stahle H, Mazur D: Influence of renal impairment on the pharmacokinetics and pharmacodynamics of oral dabigatran etexilate: an open-label, parallel-group, single-centre study. Clin Pharmacokinet 2010, 49:259-268.

doi:10.1186/1477-9560-12-25

Cite this article as: Bauersachs et al: Rivaroxaban versus enoxaparin/ vitamin $\mathrm{K}$ antagonist therapy in patients with venous thromboembolism and renal impairment. Thrombosis Journal 2014 12:25.

\section{Submit your next manuscript to BioMed Central and take full advantage of:}

- Convenient online submission

- Thorough peer review

- No space constraints or color figure charges

- Immediate publication on acceptance

- Inclusion in PubMed, CAS, Scopus and Google Scholar

- Research which is freely available for redistribution 